\title{
Mechanisms of dyspnoea and its language in patients with asthma
}

\author{
P. Laveneziana*, P. Lotti*, C. Coli*, B. Binazzi*, L. Chiti*, L. Stendardi”, \\ R. Duranti* and G. Scano**\#
}

ABSTRACT: This study hypothesises that regardless of the global score of dyspnoea intensity, different descriptors may be selected by asthmatic patients during short cardiopulmonary exercise test (SCPET) and methacholine (Mch) inhalation. It also examines whether different qualitative dyspnoea sensations can help explain the underlying mechanisms of the symptom.

Minute ventilation $\left(V^{\prime} E\right)$, tidal volume (VT) and inspiratory capacity (IC) were measured in 22 stable asthmatic patients, and the sensation of dyspnoea during Mch inhalation and SCPET was quantitatively (Borg scale) and qualitatively (descriptors) assessed. The work rate and oxygen uptake $\left(V^{\prime} \mathrm{O}_{2}\right)$ were also measured during SCPET.

Airway obstruction and hyperinflation, as measured by IC reduction, were the best correlates for dyspnoea with Mch. During SCPET, changes in WR, $V^{\prime} \mathrm{O}_{2}, V^{\prime} E$ and $V_{T}$ significantly correlated with Borg score, with $V^{\prime} E$ being the best predictor of dyspnoea; IC decreased in eight patients. Furthermore, chest tightness (68\%) was the highest reported descriptor during Mch inhalation, whereas work/effort (72\%) was the highest during SCPET.

In conclusion, obstruction/hyperinflation and work rate are highly reliable predictors of Borg rating of dyspnoea during methacholine inhalation and short cardiopulmonary exercise testing, respectively. Regardless of the global score of intensity dyspnoea, different descriptors may be selected by patients during short cardiopulmonary exercise testing and methacholine inhalation. Various qualities of dyspnoea result from different pathophysiological abnormalities.

KEYWORDS: Airway, asthma, dyspnoea, exercise, hyperinflation, methacholine

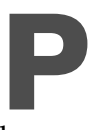

sychophysical techniques for measuring dyspnoea have long been applied and factors contributing to its variability have been reported in patients with asthma. Selfreported dyspnoea symptom ratings as a measure of intensity of dyspnoea can be estimated by employing a category ratio scale, such as a modified Borg scale [1]. With a Borg scale, the subject rates the intensity of the discomfort experienced and associated with breathing, regardless of its qualitative features. The patient's perception of his/her dyspnoea in response to change in lung function is nonspecific and assessment directed toward the intensity of dyspnoea alone may not accurately reflect the level of persistent functional abnormalities. Dyspnoea is a general term used to characterise a range of qualitatively distinct descriptors that vary in intensity [2-7]. Based on the hypothesis that various qualities of respiratory discomfort result from different pathophysiological abnormalities, language could help define one or more of the abnormalities responsible for breathing discomfort. By using the language of dyspnoea, Moy et al. [7] demonstrated that, during methacholine (Mch) inhalation, mild bronchoconstriction is associated with the sensation of chest tightness, whereas external resistive loads plus dynamic hyperinflation are associated with sensations of work/effort and an inability to take a deep breath.

During exercise the increase in motor command to ventilatory muscles relayed by interneurons high in the central nervous system to the sensory cortex (termed "corollary discharge") can be perceived as a sensation of work/effort [8-11]. KILLIAN et al. [12] stated that asthmatics who rate the intensity of dyspnoea as high during bronchoconstriction also tend to report that dyspnoea is high during exercise. However, this opinion is perhaps questionable if the role of obstruction and hyperinflation on dyspnoea during Mchinduced bronchoconstriction is considered [11] and, conversely, if little or unreported airway obstruction during a short exercise session, as opposed to a long-term session, in patients with exercise-induced asthma is taken into account [13]. To the best of the current authors' knowledge, in studies on the language of dyspnoea, asthmatics were asked to recall their experience
AFFILIATIONS

${ }^{*}$ Dept of Internal Medicine,

University of Florence, Florence, and \#Fondazione Don C. Gnocchi, Section of Respiratory Rehabilitation, Pozzolatico, Firenze, Italy.

CORRESPONDENCE

G. Scano

Dept of Internal Medicine

Section of Respiratory Medicine

Policlinico di Careggi

Viale Morgagni 85

50134 Firenze

Italy

Fax: 39055412867

E-mail: gscano@unifi.it

Received:

July 092005

Accepted after revision:

November 212005 
of breathlessness provoked by activity [4] or exercise [3], but not to describe what they experienced during exercise.

Based on the contrasting effects of airway obstruction and dynamic hyperinflation on the language of dyspnoea during Mch inhalation [7], and the finding that in short exercise sessions, an increase in lung volumes does not appear to be a crucial contributor to exercise limitation and dyspnoea intensity in severe asthma [14], the present authors hypothesised that regardless of the global score of intensity of dyspnoea, different descriptors may be selected by patients during short exercise sessions and Mch inhalation.

The aim of the present study was to ascertain whether different qualitative sensations of dyspnoea occur during Mch inhalation and exercise and if they could help explain the underlying pathophysiological mechanisms in a population of patients without exercise-induced bronchial asthma.

\section{MATERIALS AND METHODS \\ Subjects}

Twenty-two consecutive patients (14 females) aged 36-75 yrs (mean age: $41.5 \mathrm{yrs}$ ) with persistent stable bronchial asthma, according to the criteria of the International Consensus Report on Diagnosis and Treatment of Asthma [15], participated in the study. Asthma was classified as either mild or mild-tomoderate according to the frequency of symptoms, the requirement of $\beta_{2}$-agonists for the treatment of symptoms, baseline airway function, bronchial hyperresponsiveness, and a provocative concentration of Mch causing a $20 \%$ fall (PC20) in forced expiratory volume in one second (FEV1) of $<8 \mathrm{mg} \cdot \mathrm{mL}^{-1}$. None of the patients reported having a history of exerciseinduced asthma or smoking; at the time of the study, there was no clinical or laboratory evidence of any other cardiorespiratory disease. All patients were studied on three occasions. On each occasion, the patient refrained from using inhaled bronchodilators for $\geqslant 12 \mathrm{~h}$ prior to investigation. Five of the 22 patients were treated with long-acting bronchodilators and inhaled steroids $\left(<1,000 \mu \mathrm{g} \cdot \mathrm{day}^{-1}\right)$. The use of long-acting bronchodilators was withheld for $\geqslant 24 \mathrm{~h}$ before each visit. All subjects were trained in respiratory manoeuvres and were also able to perform an exercise cycling test. The research was carried out in accordance with Declaration of Helsinki (2000) of the World Medical Association. Informed consent was given by patients, and the study was approved by the local ethics committee.

\section{Functional evaluation}

A baseline pulmonary function test was performed in order to measure static and dynamic lung volumes. Spirometry and functional residual capacity (Vmax 29c; SensorMedics, Yorba Linda, CA, USA) were assessed in accordance with recommended standards [16]. Flow was measured using a mass flowmeter (Vmax 29c; SensorMedics) attached to the mouthpiece and its integral was used to measure tidal volume $(V T)$. Respiratory rate (RR) and minute ventilation $\left(V^{\prime} \mathrm{E}\right)$ were also measured.

\section{Methacholine challenge testing}

Each patient then undertook a Mch aerosol inhalation test, according to a standardised tidal breathing procedure [17]. Increasing concentrations of Mch-chlorhydrate in normal PBS solution (prepared by the University Hospital Pharmacy, AOUC Azienda Ospedaliero-Universitaria di Careggi, Careggi, Firenzi, Italy) were inhaled from a nebuliser (Model 646, DeVilbiss, Somerset, PA, USA), resulting in an output of $0.13 \mathrm{~mL} \cdot \mathrm{min}^{-1}$. With this method, $4 \mathrm{~mL}$ of solution were placed in the nebuliser, and inhalation continued during tidal breathing for $2 \mathrm{~min}$. The Mch solution was stored at $4^{\circ} \mathrm{C}$ and was nebulised at room temperature. Normal PBS solution was inhaled first, followed at 5-min intervals by Mch in two-fold increasing concentrations from 0.031 to $8 \mathrm{mg} \cdot \mathrm{mL}^{-1}$. The test was withheld at the pre-set FEV1 fall (PC20). FEV1 and inspiratory capacity (IC) were measured for 1 to $1.5 \mathrm{~min}$ after inhalation of each concentration of Mch. Two measurements of FEV1 and IC were performed, and the best values were used. The PC20 was noted from the log dose-response curve.

\section{Cardiopulmonary exercise testing}

Patients performed a short cardiopulmonary exercise test (sCPET) on an electrically braked cycle ergometer (Ergometrics 800; SensorsMedics). Before exercise and while seated on the cycle ergometer, the subject breathed for $3 \mathrm{~min}$ through an unidirectional valve (Hans Rudolph, Kansas City, MO, USA), with the expired air going to a universal exercise testing system (Ergometrics 800; SensorsMedics). After 3 min of spontaneous resting breathing, subjects performed an IC pedalling at an $\mathrm{rpm}$ of 50-60 cycles $\cdot \mathrm{min}^{-1}$, initially at zero load. After 3 min of pedalling without load, workload was increased in 20-30 W steps every minute until exhaustion. The incremental workload was tailored in order to obtain a short exercise session (6-8 min). Maximum power output was defined as the highest level of exercise that could be sustained. Expired gas was analysed for $V^{\prime} \mathrm{E}$, oxygen uptake $\left(V^{\prime} \mathrm{O}_{2}\right)$, and carbon dioxide production $\left(V^{\prime} \mathrm{CO}_{2}\right)$ using breath analysis from the Vmax System (SensorMedics). $V^{\prime} \mathrm{CO}_{2}$ and $V^{\prime} \mathrm{O}_{2}$ were expressed as STPD (standard temperature and pressure, dry) and as a percentage of predicted maximum [18]. $V^{\prime} E, R R$ and $V \mathrm{~T}$ were recorded continuously, whereas IC was gathered during the last $30 \mathrm{~s}$ of each workload. Anaerobic threshold was assessed using the V-slope method [19]. Cardiac frequency was continuously measured using a 12-lead electrocardiogram (Esaote Spa, Firenze, Italy) and oxygen saturation was measured using a pulse oxymeter (NPB 290; Nellcore Puritan Bennett, Pleasanton, CA, USA). Blood pressure was recorded at rest and every $2 \mathrm{~min}$ during exercise and recovery to baseline levels.

\section{Assessment of dyspnoea and leg effort}

After inhalation of saline solution and each dose of Mch, and every minute during SCPET, the subjects were requested to rate their breathing discomfort, matching their subjective magnitude to a number on the Borg scale [1].

The quality of dyspnoea was evaluated using a 15-item questionnaire of descriptors of dyspnoea [7]. This was filled out retrospectively during the first screening visit. Eight descriptors were chosen that the patients were familiar with during spontaneous asthma and daily living activities, including mild-to-moderate exercise (table 1). Many patients were unable to retrospectively select or understand other descriptors from the proposed questionnaire. This is in line with the limitations of the language of dyspnoea. It cannot be assumed 


TABLE 1 Descriptors of dyspnoea
I feel out of breath
My chest feels tight
I cannot take a deep breath
My breathing requires an inspiratory effort
My breathing requires an expiratory effort
I feel hunger for more air
My breathing is shallow
I feel that my breathing is rapid

that all individuals share a common understanding of the same descriptors; differences in language, race, culture, and the manner in which concepts or symptoms are held can influence a subject's perception of dyspnoea. In practice, in the screening visit patients were capable of understanding some descriptors but not others, such as "concentration", "gasping for breath", "my breath stops", "I am breathing more", "I feel that I am smothering" and "my breath does not go in all the way". On the days of the study, the same questionnaire was employed to describe the sensation experienced during the two tests before Borg rating.

Patients were asked to select three phrases that best described the quality of dyspnoea. If more than three were chosen, the subject was asked to select the three that best described the respiratory discomfort and quality of dyspnoea. Overall intensity of breathing and quality of dyspnoea were then assessed during bronchoconstriction at each concentration of Mch and at each step of exercise. At the end of Mch and sCPET, patients had to select descriptor(s) from the previous list to express their dyspnoea sensation.

Leg effort was also measured, every minute during sCPET, using a modified Borg scale.

\section{Protocol}

The study was conducted on 3 days. During the first visit, patients performed a baseline pulmonary function test. At the second and third visit, each patient was randomly administered either an Mch aerosol inhalation test or a cardiopulmonary exercise test, tailored according to SUMAN et al. [13].

\section{Statistics}

Results are expressed as mean $\pm \mathrm{SD}$, unless otherwise indicated. The responses to Mch inhalation and sCPET were compared using a paired t-test. The relationship between Borg as a dependent variable and FEV1, IC and ventilatory variables as independent variables was assessed using linear regression analysis. The generalised linear model and multiple regression (Wald Chi-squared) were also used. In the present analysis, Wald Chi-squared gives the significance of the model, i.e. it assesses whether the variability of the dependent variable is significant as predicted from one or more independent variables. The significance of a single independent variable in predicting the variability of the dependent variable is given in terms of $\mathrm{z}$. Thereafter, to predict the variability of the Borg score, a stepwise multiple regression analysis was performed for pooled data; the data of the analysis were considered acceptable only if the variables entered in the final model were the same as those obtained by general linear model analysis. A p-value of $<0.05$ was considered significant.

\section{RESULTS}

\section{Spirometry}

Table 2 presents the anthropometric and spirometric data of the 22 subjects. Of the patients, 19 had mild asthma (FEV1 $\geqslant 80 \%$ predicted), two had moderate asthma (FEV1 60-80\% pred) and one had severe asthma (FEV1 $\leqslant 60 \%$ pred). Despite a mild increase in total lung capacity in five subjects, emphysema was not present in any of them. This was shown by the following: 1) normal values of diffusing capacity of the lung for carbon monoxide/alveolar volume (86-95\% pred); 2) lack of chest radiograph findings of the disease; 3) no smoking history; and 4) short duration of asthma.

\section{Methacholine challenge testing}

During Mch challenge, IC decreased $(\Delta \mathrm{IC} 0.53 \pm 0.33 \mathrm{~L})$ in all but one patient, and in each of them, the relationship of Borg with FEV1 $\left(p<0.02, \mathrm{r}^{2} \geqslant 0.635\right)$ and IC $\left(\mathrm{p}<0.02 ; \mathrm{r}^{2} \geqslant 0.867\right)$ was highly significant. Moreover, as shown by the relationship between $\triangle \mathrm{IC}$ and the change in Borg per unit change in FEV1, hyperinflation explained part of the variability in Borg that was not explained by the change in FEV1 $\left(p<0.003, r^{2}=0.41\right)$.

\section{Cardiopulmonary exercise testing}

Exercise capacity was normal in all but two patients, in whom it was reduced (maximal oxygen uptake of 75.6 and $75.8 \%$ pred). None of the subjects experienced bronchoconstriction during exercise. The anaerobic threshold, calculated using the V-slope method, was reached; no patient desaturated during the test. A decrease in IC was noted in eight patients. Table 3 shows the attained peak values. Exercises were stopped due to leg effort in 15 patients, dyspnoea in six patients and for both reasons in one patient. Peak dyspnoea and peak leg effort were no different at the peak of exercise. Peak dyspnoea during sCPET (Borg $7.3 \pm 2$ arbitrary units (au) at peak exercise) was significantly higher than dyspnoea at the end of Mch inhalation (Borg $5.3 \pm 1.6 \mathrm{au})(\mathrm{p}<0.0009)$, but this is quite

\section{TABLE 2 Anthropometric and baseline lung function in 22} patients with asthma

$\begin{array}{lc}\text { Age yrs } & 35.5 \pm 14.3 \\ \text { Male/female } \mathbf{n} & 7 / 13 \\ \text { BMI } \mathbf{~ k g} \cdot \mathbf{m}^{-\mathbf{2}} & 26 \pm 8 \\ \text { FEV1 L } & 3.5 \pm 1.1(109 \pm 24.9) \\ \text { FVC L } & 4.5 \pm 1.2(118 \pm 17) \\ \text { FEV1/FVC \% } & 76 \pm 13.8 \\ \text { IC L } & 2.9 \pm 0.8(104.4 \pm 22) \\ \text { FRC L } & 3.8 \pm 0.9(123.4 \pm 13) \\ \text { TLC L } & 6.8 \pm 1.5(118 \pm 13) \\ \text { PC20 FEV1 } \mathbf{~ m g} \cdot \mathbf{m l}^{-\mathbf{1}} & 1.2(0.062-8)\end{array}$

Data are presented as mean \pm SD (\% predicted) and geometric mean (range) unless otherwise stated. BMI: body mass index; FEV1: forced expiratory volume in one second; FVC: forced vital capacity; IC: inspiratory capacity; FRC: functional residual capacity; TLC: total lung capacity; PC20: provocative concentration of methacholine causing $20 \%$ fall in FEV 1 . 


\begin{tabular}{|c|c|}
\hline \multicolumn{2}{|c|}{ Values at peak of exercise } \\
\hline WR W & $152 \pm 54$ \\
\hline$V^{\prime} \mathrm{O}_{2} \mathrm{~mL} \cdot \mathrm{min}^{-1}$ & $2329 \pm 960$ \\
\hline$V^{\prime} \mathrm{O}_{2} \%$ pred & $107.7 \pm 24.6$ \\
\hline$V^{\prime} \mathrm{O}_{2} \mathrm{~mL} \cdot \mathrm{kg}^{-1} \cdot \mathrm{min}^{-1}$ & $35.9 \pm 13.2$ \\
\hline$V^{\prime} \mathrm{CO}_{2} \mathrm{~mL} \cdot \mathrm{min}^{-1}$ & $2396 \pm 890$ \\
\hline fc $\%$ pred & $91.1 \pm 6.3$ \\
\hline $\mathrm{O}_{2}$ pulse $\mathrm{mL} \cdot$ beat $^{-1}$ & $13.7 \pm 4.9$ \\
\hline$V^{\prime} E L \cdot \min ^{-1}$ & $82 \pm 24.6$ \\
\hline VT L & $2.3 \pm 0.7$ \\
\hline RR cycles $^{-1}$ & $35.6 \pm 6.7$ \\
\hline Dyspnoea au & $6.9 \pm 2.2$ \\
\hline Leg effort au & $7.6 \pm 2.2$ \\
\hline \multicolumn{2}{|c|}{$\begin{array}{l}\text { Data are presented as mean } \pm \mathrm{SD} \text {. WR: work rate; } V^{\prime} \mathrm{O}_{2} \text { : oxygen uptake; } V^{\prime} \mathrm{CO}_{2} \text { : } \\
\text { carbon dioxide production; fC: cardiac frequency; \% pred: \% predicted; } \mathrm{O}_{2} \text { : } \\
\text { oxygen; } V^{\prime} \mathrm{E} \text { : minute ventilation; } V \mathrm{~T} \text { : tidal volume; RR: respiratory rate; au: } \\
\text { arbitrary units at peak exercise. }\end{array}$} \\
\hline
\end{tabular}

logical because exercise was stopped at the maximal effort, while Mch was stopped at a pre-set FEV1 fall.

Unlike changes in $\mathrm{IC}$, changes in work rate, $V^{\prime} \mathrm{E}, V^{\prime} \mathrm{O}_{2}$ and $V \mathrm{~T}$ were significantly correlated with changes in the Borg score $(\mathrm{p}<0.05, \mathrm{r} \geqslant 0.65)$, with $V^{\prime} \mathrm{E}$ being the best predictor of dyspnoea during sCPET in each subject and in patients as a group $($ Wald Chi-squared $=572.5$, probability Chi-squared $=$ $0.000, \mathrm{z}=5.52$; multiple regression analysis, $\mathrm{p}<0.0001, \mathrm{r}^{2}=0.66$; fig. 1). A close relationship was found between $\Delta$ dyspnoea and $\Delta$ leg effort per unit change in $\mathrm{W}\left(\mathrm{p}=0.0001, \mathrm{r}^{2}=0.55\right)$. In eight patients with a similar IC decrease with both Mch and sCPET (Mch 0.51 $\pm 0.3 \mathrm{~L}$; sCPET 0.52 $\pm 0.22 \mathrm{~L}$ ), the differences in Borg from control were greater $(\mathrm{p}<0.05)$ with $\mathrm{sCPET}(6.9 \pm 1.6 \mathrm{au})$ than with Mch $(4 \pm 2 \mathrm{au})$.

\section{Dyspnoea descriptors}

Figure 2 shows the percentage of descriptors selected at the end of the two tests. With Mch challenge, $68 \%$ of the responses (15 patients) were chest tightness, 18\% (four patients) were inspiratory effort and $14 \%$ (three patients) were expiratory

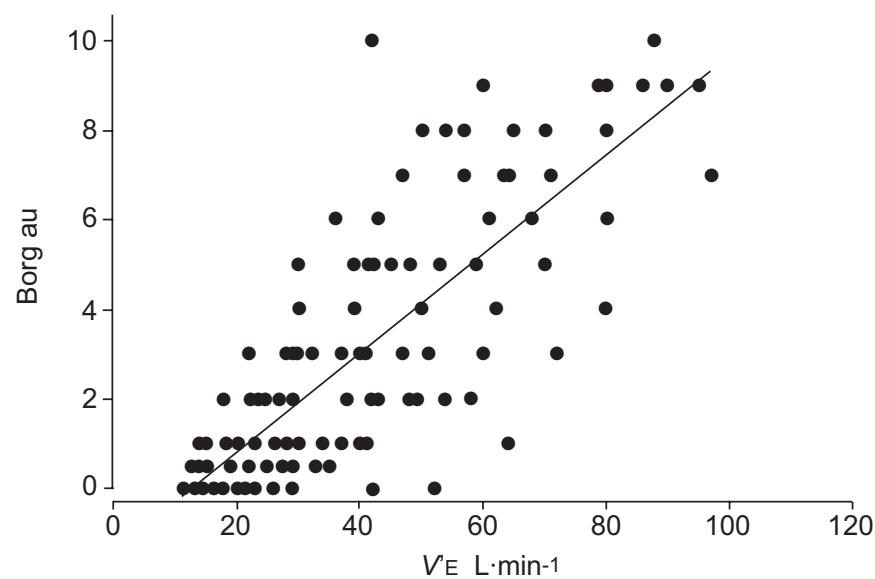

FIGURE 1. Relationship between Borg and minute ventilation ( $\left.V^{\prime} E\right)$ during short cardiopulmonary exercise test (pooled data). Wald Chi-squared: 572.5; probability Chi-squared: $0.000 ; r^{2}: 66 \%$. au: arbitrary units.

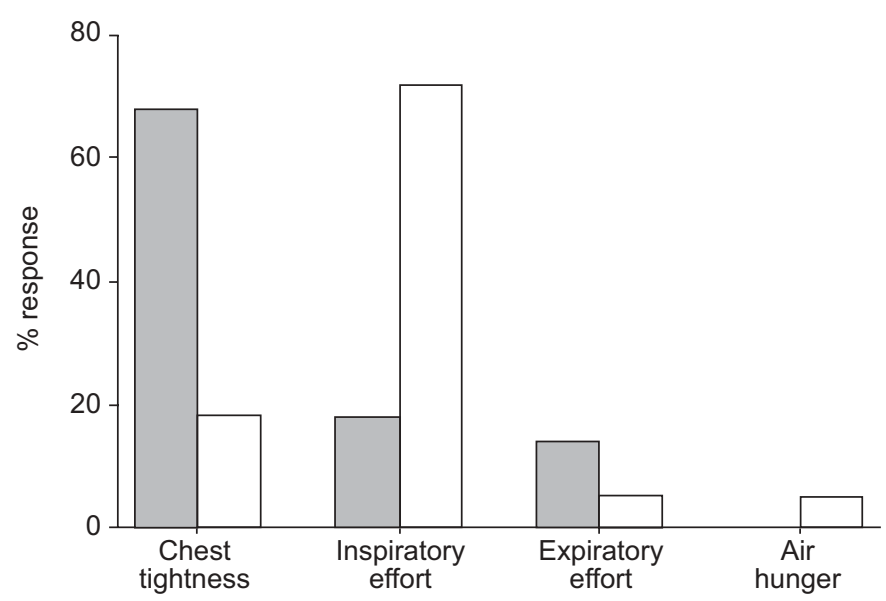

FIGURE 2. Percent responses of descriptors selected after methacholine inhalation ( $\square$ ) and short cardiopulmonary exercise test $(\square)$.

effort. With sCPET, $72 \%$ of the responses (16 patients) were inspiratory effort, $18 \%$ (four patients) were chest tightness, and the last $10 \%$ were equally distributed between inspiratory effort and air hunger (two patients). The percentage of descriptors in the eight patients who similarly hyperinflated during both tests were as follows: with Mch, $60 \%$ were chest tightness, $10 \%$ were inspiratory effort and 30\% were expiratory effort; with sCPET, $90 \%$ were inspiratory effort and $10 \%$ were chest tightness (fig. 3).

Neither quantitative nor qualitative change perceptions were age-related.

\section{DISCUSSION}

The present study found that: 1) airway obstruction and hyperinflation were the best predictors of dyspnoea with Mch challenge, whereas work rate, $V^{\prime} \mathrm{O}_{2}, V^{\prime} \mathrm{E}$ and $V \mathrm{~T}$ were the best predictors of dyspnoea in subjects undergoing SCPET; and 2) chest tightness was the most reported descriptor during Mch inhalation, whereas effort was frequently reported during exercise. These data suggest different underlying mechanisms

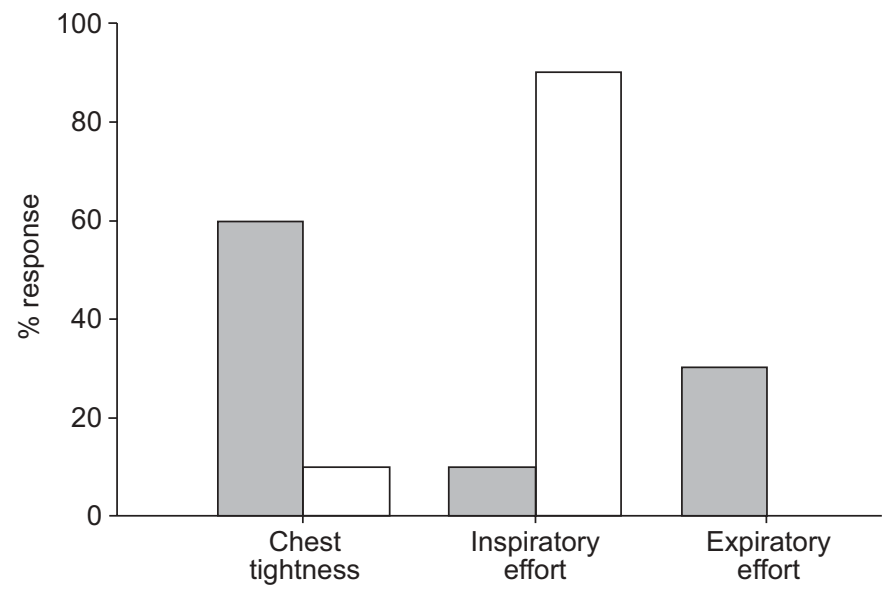

FIGURE 3. Percent responses of descriptors selected by the eight subjects who similarly hyperinflated at the end of the two tests. $\square$ : methacholine inhalation; $\square$ short cardiopulmonary exercise test. 
of dyspnoea during Mch inhalation and a short exercise session.

The novel findings of the study are as follows. 1) Whereas Mor et al. [7] employed the language of dyspnoea to test the hypothesis that patients perceive the same quality of dyspnoea during mild bronchoconstriction and external resistive load, the present study was devised to validate the hypothesis that asthmatics may select different descriptors during Mch and exercise. To the present authors' knowledge this comparison has not yet been performed. 2) In studies on the language of dyspnoea, patients were simply asked to recall their experience of breathlessness provoked by activity [4] or exercise [3]; the present study is the first attempt to evaluate the relationship between the language of dyspnoea and the change in lung function during exercise in asthmatics. 3) Various qualities of dyspnoea result from different clinical situations. In particular, while chest tightness was the most selected descriptor with Mch, inspiratory effort was the most selected descriptor during sCPET.

Dyspnoea is multifactorial $[9,10]$ and the exact mechanism that causes dyspnoea in asthmatics is not fully understood. It has been suggested that mechanical factors, such as load on and activity of the ventilatory muscles [10] associated with pulmonary hyperinflation [9-11], temporal adaptation [10, 20] and bronchial hyperresponsiveness [5, 20], as well as psychological, emotional and cognitive factors [21] influence the perception of dyspnoea during bronchoconstriction in asthma. Experimental evidence indicates that hyperinflation probably plays an important role in the pathogenesis of dyspnoea. LOUGHEED et al. [11] found that an increased endexpiratory lung volume (EELV) was the single greatest contributor to dyspnoea; the best physiological correlate of dyspnoea relief after administration of salbutamol was a return of EELV to baseline. In line with the above results [11] and a recent contribution of the current authors [22], the present data confirm the dominant role of hyperinflation on dyspnoea during a relatively minor Mch-induced bronchoconstriction, when FEV1 had declined by only $20 \%$.

In contrast, the vast majority of patients did not hyperinflate during sCPET. Indirect evidence suggests that hyperinflation is not the sole mechanism of dyspnoea: some patients with chronic asthma have a minimal increase in lung volume but are quite symptomatic. Previous studies have found that there is no airway obstruction or dynamic hyperinflation (DH) during short-term intense exercise sessions in mild-to-moderate asthma [13, 14]. SUMAN et al. [13] reported that there was little or no airway obstruction during short-term exercise, with obstruction and mild DH only evident during the late stage of long-term exercise sessions in patients with exercise-induced asthma. Moreover, no relationship was found between dyspnoea and $\mathrm{DH}$ during short- or long-term exercise sessions [13]. Likewise, BARREIRO et al. [14] demonstrated that an exerciseinduced increase in lung volume did not appear to be a crucial contributor to both exercise limitation and dyspnoea intensity in patients with severe asthma, as shown by the fact that: 1) correlation coefficients were reported to be similar to those obtained with resting IC; and 2) the decrease in IC during exercise was not statistically significant in patient the subgroup with the greatest peak Borg score during exercise [14].
The present data show that only a minority of asthmatics hyperinflated during exercise. In the patients as a whole, in line with an increased central respiratory drive, work rate, $V^{\prime} \mathrm{O}_{2}, V^{\prime} \mathrm{E}$ and $V \mathrm{~T}$ predicted a consistent dyspnoea score on the Borg scale. These data are in line with the results of MAHLER et al. [23] who presented the high predictive value of breathing pattern variables on Borg rating during exercise. The observation that there was a greater increase in Borg during sCPET (fig. 2) in the eight patients who hyperinflated during both Mch challenge and SCPET, further suggests that factors other than hyperinflation play a role in dyspnoea during short-term incremental exercise.

As a corollary, the increased central output was probably shared between respiratory muscles and peripheral muscles. This was suggested by the strong relationship between $\Delta$ dyspnoea and $\Delta$ leg effort per unit change in W. However, in line with previous observations [10], leg effort was a more frequently reported reason than dyspnoea for stopping exercise, suggesting some peripheral muscle deconditioning.

The many descriptors that characterise bronchial asthma indicate that different pathophysiological mechanisms are potentially in play [5]. LOUGHEED et al. [11] showed that asthmatics selected two descriptors during Mch-induced bronchoconstriction: the first was chest tightness associated with airway obstruction and the second, inspiratory effort coincident with the association of increased airway obstruction with hyperinflation. For any given FEV1 decrease, a progressive increase in airway narrowing was associated with a greater shift in the Borg score of inspiratory effort. In induced asthma, Moy et al. [7] showed that the initial sensation of chest tightness reflected the breathing discomfort caused by mild bronchoconstriction; with a more severe FEV1 decline and hyperinflation, the sensation of work or effort of breathing was noted. Chest tightness may arise from the stimulation of sensory receptors within the lungs [7] mediated through vagal and autonomic pathways [7, 24]. Rapidly adapting (irritant) receptors and $\mathrm{C}$-fibres may respond to local inflammation of the airways and contribute to dyspnoea associated with bronchoconstriction $[9,25,26]$.

Descriptors comprised in the cluster work/effort are selected as common for most diagnoses and characterise several clinical conditions [2]. Regardless of the specific disorder, work/effort intensifies during exercise. The increase in motor command to ventilatory muscles relayed by interneurons high in the central nervous system to the sensory cortex (or "corollary discharge" $)[8,11]$ can be perceived as a sensation of effort. The cluster work/effort is likely to be associated with both dynamic hyperinflation and more severe airway obstruction. Unlike a previous statement [27] hyperinflation is not the stimulus that induces tightness; rather, it induces the perception of increased effort [24].

The present data show that for Mch, chest tightness was the most selected descriptor, with the responses characterised by work/effort (either inspiratory or expiratory) being much less reported. These data suggest that, despite the important contribution of hyperinflation $(\Delta \mathrm{IC})$ to the quantity of the sensation (Borg ratings), airway obstruction plays a dominant role and hyperinflation a minor one in the quality of the 
sensation (fig. 2). Furthermore, in the eight patients who hyperinflated during Mch and SCPET, chest tightness dominated over inspiratory effort. In addition, the relevant increase in the percentage of the expiratory effort descriptor suggests the potential role of expiratory flow limitation on dyspnoea perception.

Conversely, the data during sCPET show that inspiratory effort was the most selected descriptor, with chest tightness, expiratory effort and air hunger responses selected less frequently. These data indicate the prevalent contribution of the respiratory drive to both intensity and quality of dyspnoea during SCPET. In the patients who hyperinflated in the two conditions, inspiratory effort dominated during SCPET, reflecting greater inspiratory pressure production.

In conclusion, obstruction/hyperinflation and work rate in asthmatic patients are predictors of the Borg rating of dyspnoea during methacholine challenge and short cardiopulmonary exercise testing, respectively. Various qualities of dyspnoea result from different pathophysiological abnormalities. The use of descriptors of dyspnoea may contribute to understanding of the mechanisms causing discomfort.

\section{REFERENCES}

1 Borg GA. Psychophysical basis of perceived exertion. Med Sci Sports Exercise 1982; 14: 377-381.

2 Simon PM, Schwartzstein RM, Weiss JW, Fencl V, Teghtsoonian M, Weimberger SE. Distinguishable types of dispnea in patients with shortness of breath. Am Rev Respir Dis 1990; 42: 1009-1014.

3 Elliott MW, Adams L, Cockcroft A, MacRae KD, Murphy K, Guz A. The language of breathlessness. Use of verbal descriptors by patients with cardiopulmonary disease. Am Rev Respir Dis 1991; 144: 826-832.

4 Mahler DA, Harver A, Lentine T, Scott JA, Beck K, Schwartzstein RM. Descriptors of breathlessness in cardiorespiratory diseases. Am J Respir Crit Care Med 1996; 154: 1357-1363.

5 Killian KJ, Watson R, Otis J, St Amand TA, O'Byrne PM. Symptom perception during acute bronchoconstriction. Am J Respir Crit Care Med 2000; 162: 490-496.

6 Mahler DA, Harver A. Do you speak the language of dyspnea? Chest 2000; 117: 928-929.

7 Moy ML, Weiss JW, Sparrow D, Israel E, Schwartzstein RM. Quality of dyspnea in bronchoconstriction differs from external resistive loads. Am J Respir Crit Care Med 2000; 162: 451-455.

8 McCloskey DI. Corollary discharges motor commands and perception. In: Brookhart JM, Mountcastle VB, eds. The nervous system. Handbook of Physiology. Section 1, vol. 2, part 2. Bethesda, MD, USA, American Physiological Society, 1981; pp. 1415-1447.

9 Manning HL, Schwartzstein RM. Pathophysiology of dyspnea. N Eng J Med 1995; 333: 1547-1553.

10 Killian KJ, Campbell EJ. Dyspnoea. In: Roussos C, ed. The Thorax. Part B. New York, NY, USA, Marcel Dekker, 1995; pp. 1709-1747.

11 Lougheed MD, Lam M, Forkert L, Webb KA, O’Donnell DE. Breathlessness during acute bronchoconstriction in asthma. Pathophysiologic mechanisms. Am Rev Respir Dis 1993; 148: 452-459.

12 Killian KJ, Summers E, Watson RM, O'Byrne PM, Jones NL, Campbell EJ. Factors contributing to dyspnoea during bronchoconstriction and exercise in asthmatic subjects. Eur Respir J 1993; 6: 1004-1010.

13 Suman OE, Babcock MA, Pegelow DF, Jarjour NN, Reddan WG. Airway obstruction during exercise in asthma. Am J Respir Crit Care Med 1995; 152: 24-31.

14 Barreiro E, Gea J, Sanjuas C, Marcos R, Broquetas J, MilicEmili J. Dyspnoea at rest and at the end of different exercises in patients with near-fatal asthma. Eur Respir $J$ 2004; 24: 219-225.

15 International Consensus Report on Diagnosis and Treatment of Asthma. National Heart, Lung, and Blood Institute, National Institutes of Health, Bethesda, Maryland 20892. Publication no. 92-3091. Eur Respir J 1992; 5: 601-641.

16 Standardized lung function testing. Official statement of the European Respiratory Society. Eur Respir J 1993; 16: Suppl. 9, 1-100.

17 Sterk PJ, Fabbri LM, Quanjer PH, et al. Airway responsiveness. Standardized challenge testing with pharmacological, physical and sensitizing stimuli in adults. Report Working Party Standardization of Lung Function Tests, European Community for Steel and Coal. Official Statement of the European Respiratory Society. Eur Respir J 1993; 16: Suppl. 6, 53-83.

18 Jones NL, Campbell AJ. Clinical Exercise Testing. 2nd Edn. Philadelphia, PA, USA, WB, Saunders, 1982.

19 Beaver WL, Wasserman K, Whipp BJ. A new method for detecting anaerobic threshold by gas exchange. J Appl Physiol 1986; 60: 2020-2027.

20 Burdon JG, Juniper EF, Killian KJ, Hargreave FE, Campbell EJ. The perception of breathlessness in asthma. Am Rev Respir Dis 1982; 126: 825-828.

21 Jones PW, Wilson RC. Cognitive aspects of breathlessness. In: Adams L, Guz A, eds. Respiratory Sensation. New York, NY, USA, Marcel Dekker, 1996; pp. 311-339.

22 Filippelli M, Duranti R, Gigliotti F, et al. Overall contribution of chest wall hyperflation to breathlessness in asthma. Chest 2003; 124: 2164-2170.

23 Mahler DA, Faryniarz K, Lentine T, Ward J, Olmstead EM, O'Connor GT. Measurement of breathlessness during exercise in asthmatics. Predictor variables, reliability, and responsiveness. Am Rev Respir Dis 1991; 144: 39-44.

24 Binks AP, Moosavi SH, Banzett RB, Schwartzstein RM. "Tightness" sensation of asthma does not arise from the work of breathing. Am J Respir Crit Care Med 2002; 165: 78-82.

25 Paintal AS. Vagal sensory receptors and their reflex effects. Physiol Rev 1973; 53: 159-227.

26 Taguchi O, Kikuchi Y, Hida W, et al. Effects of bronchoconstriction and external resistive loading on the sensation of dyspnoea. J Appl Physiol 1991; 71: 2183-2190.

27 Permutt S, Fessler HE, Brower RG, Kosnik E. Breathlessness in acute asthma. In: Jones NL, Killian KJ, eds. Breathlessness. The Campbell Symposium. Hamilton, Boehringer Ingelheim, 1992; pp. 60-65. 